\title{
Electrocardiography Device with PIC18F4550 Microcontroller Using Different Communication Protocols
}

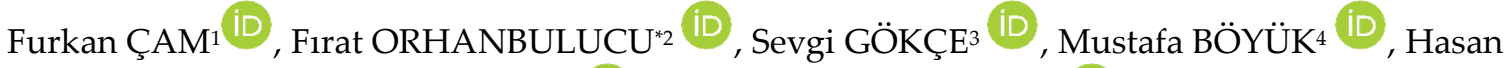 \\ AKYÜREK $^{5}$ iD Ömer Galip SARAÇOĞLU6 ${ }^{6}$ iD
}

${ }^{1}$ Erciyes University, Dept. of Electrical Electronics Engineering, Kayseri, Turkey

*2Inonu University, Dept. of Biomedical Engineering, Malatya , Turkey

3Inonu University, Dept. of Biomedical Engineering, Malatya , Turkey

${ }^{4}$ Kocaeli University, Dept. of Aircraft Electrical Electronics, Kocaeli , Turkey

${ }^{5}$ Erciyes University, Dept. of Electrical Electronics Engineering, Kayseri, Turkey

${ }^{6}$ Erciyes University, Dept. of Electrical Electronics Engineering, Kayseri, Turkey

(furkancam_38@hotmail.com, firat.orhanbulucu@inonu.edu.tr, sevgi.gokce@inonu.edu.tr, mustafa.boyuk@kocaeli.edu.tr, akyurek94hasan@gmail.com, saracog@erciyes.edu.tr)

\begin{abstract}
Many people suffer from heart disease around the world. To the problems of people with heart disease understand, it is important that monitor heart movements and intervene immediately. One of the ways to monitor heart movements is to examine the Electrocardiography of individuals. In this study, a low-cost ECG device was designed using the PIC18FF4550 microcontroller. In the designed device, the ECG signal received from the individual is displayed on the LCD device screen, which is set as a Turkish interface. At the same time, thanks to the Bluetooth module in the ECG device, it can be monitored simultaneously from electronic devices such as phones, tablets, and computers. In this way, users will be able to monitor ECG data on any electronic device with low cost and high performance.
\end{abstract}

Keywords : Electrocardiography Device, PIC18F4550 Microcontroller, Bluetooth module

\section{Introduction}

In the world, many people die due to diseases such as chronic diseases or cardiovascular diseases that require urgent interventions. Today, cardiovascular diseases are seen as the biggest cause of death. This result is on average one-third of total deaths. It has been observed that with the increase in the average age of the human population, heart diseases have also increased, and therefore deaths have increased compared to other deaths worldwide [1,2]. For this reason, it has been stated in the literature that monitoring heart movements has become important [2]. Electrocardiography (ECG) is one of the most common methods used to monitor heart movements and diagnose cardiovascular diseases. ECG is an advantageous and widely used method due to its non-invasiveness, easy application, short record duration, and cheapness. ECG takes the heart's electrical activity with the help of electrodes and is a valuable method used in the diagnosis of rhythm disorders. In addition, it is of great importance for 
rapid and accurate measurement of biological signals[3]. Today, devices such as smartphones and tablets are widely used and people can now follow certain physiological symptoms instantaneously thanks to the apparatuses attached to these devices [4]. Various studies have been conducted in the literature to monitor physiological movements, especially in the biomedical field, using mobile devices [5-7]. De Lucena et al. used the PIC18F45K20 microcontroller to receive the ECG signal from the user and show it on the mobile phone screen in real-time[9]. It has been observed that using Labview and microprocessor-based ECG measurement systems are also available in the literature $[2,8,10]$. Looking at the studies using PIC18F4550, Logeshwari and Subhalakshmi succeeded in transferring the signals to the mobile device using an ECG simulator in their study [11]. In another study, Demir et al. [12] designed a microcontroller-controlled ECG simulator and observed the ECG signal on the LCD screen.

In this study, an ECG device was designed using the PIC18F4550 microcontroller to simultaneously monitor the heart movements from electronic devices such as smartphones, tablets, computers, and the screen of the designed device. The designed device aimed to monitor the ECG taken from the individual using the HC06 Bluetooth module, simultaneously on the device screen and electronic devices such as smartphones, tablets, and computers. The interface use of the designed ECG device is designed in Turkish. In the second part of the study, the design phase of the ECG device and the materials used, and in the third part are mentioned the results obtained from the experimental studies. In the 4 th chapter, the study was evaluated based on the results.

\section{Design Of Electrocardiography (Ecg) Device}

In this section, information is given about the working principles and functions of the circuit units of the designed device. Components of the ECG device designed in the study; The electrodes used to detect ECG signals consist of an amplifier stage to amplify the signals received with these electrodes, filtering stages that will allow the passage of noiseless, clean ECG signals through the signal at the amplifier output, and layers that will display these signals. In addition, ECG device transfer them to the monitoring devices. The block diagram of the study is given in Figure 1.

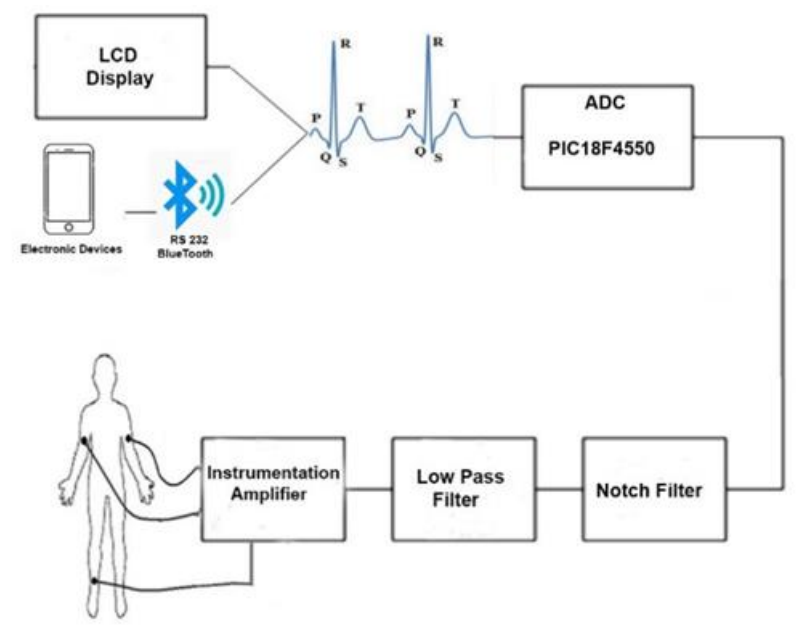

Figure 1. Block diagram of the study

\subsection{Instrumentation Amplifier and Filtering}

The ECG signal has a frequency band between $0.5 \mathrm{~Hz}$ and $150 \mathrm{~Hz}$ and an amplitude of $\pm 2 \mathrm{mV}$. ECG signals are with small amplitude and mixed with electrical noise. It is necessary to separate such a small ECG signal from noise and amplify it. The part where ECG signals are strengthened is the preamplifier. The input impedance and common-mode suppression ratio (CMRR) of this stage must be very large $[2,13]$. 
In the study, A low pass filter and a notch filter were used to remove noise from amplified ECG signals. A low-pass filter with a cutoff frequency of $150 \mathrm{~Hz}$ generally is used to clean the noise originating from the human body. A notch filter, also known as a $50 \mathrm{~Hz}$ band-stop filter, was used to suppress the noise originating from the electrical network [14]. The instrumentation amplifier and filter circuit designed with the simulation program is given in Figure 2.

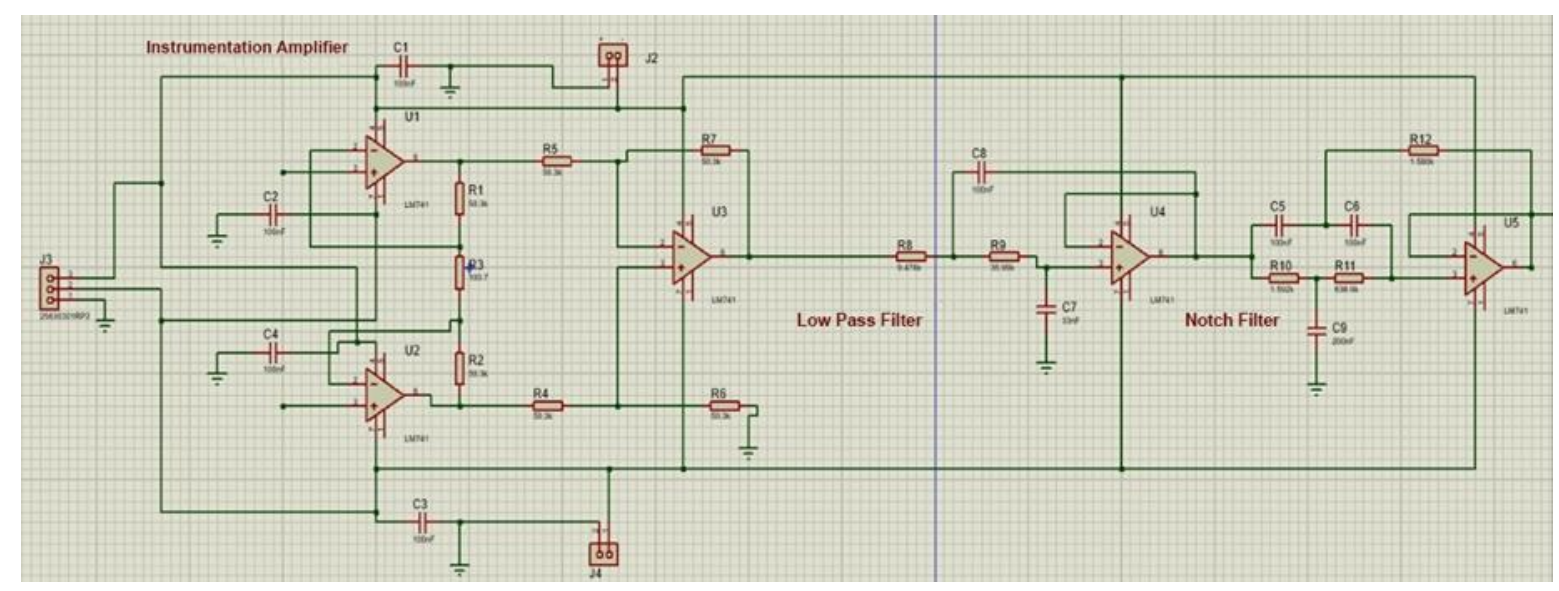

Figure 2. Instrumentation amplifier and filter circuit

\subsection{Analog-digital conversion of ECG signal}

PIC18F4550 microcontroller is used to convert analog data obtained from analog circuit blocks to digital. The used microcontroller has high computational performance and is inexpensive in terms of cost. 10-bit digital data was obtained from ECG signals by applying the Analog-Digital Converter (ADC) process with the PIC18F4550 microcontroller, and the obtained data is displayed on the LCD screen that offers an interactive interface to the user. Figure 3 shows the simulation and LCD screen interface obtained in the drawing program. The obtained data can also be sent to various devices via RS232 which is a wired communication type or HC06 Bluetooth. The digital part of the ECG device designed in the simulation program is given in Figure 4. Before transferring the designed system to the card, a simulation program was used to test the data flow and output, and the data was transferred via serial communication and tested and analyzed. ECG output signals are seen on the simulation screen given in simulation Figure 5. Simulation testing was performed using a real ECG signal.
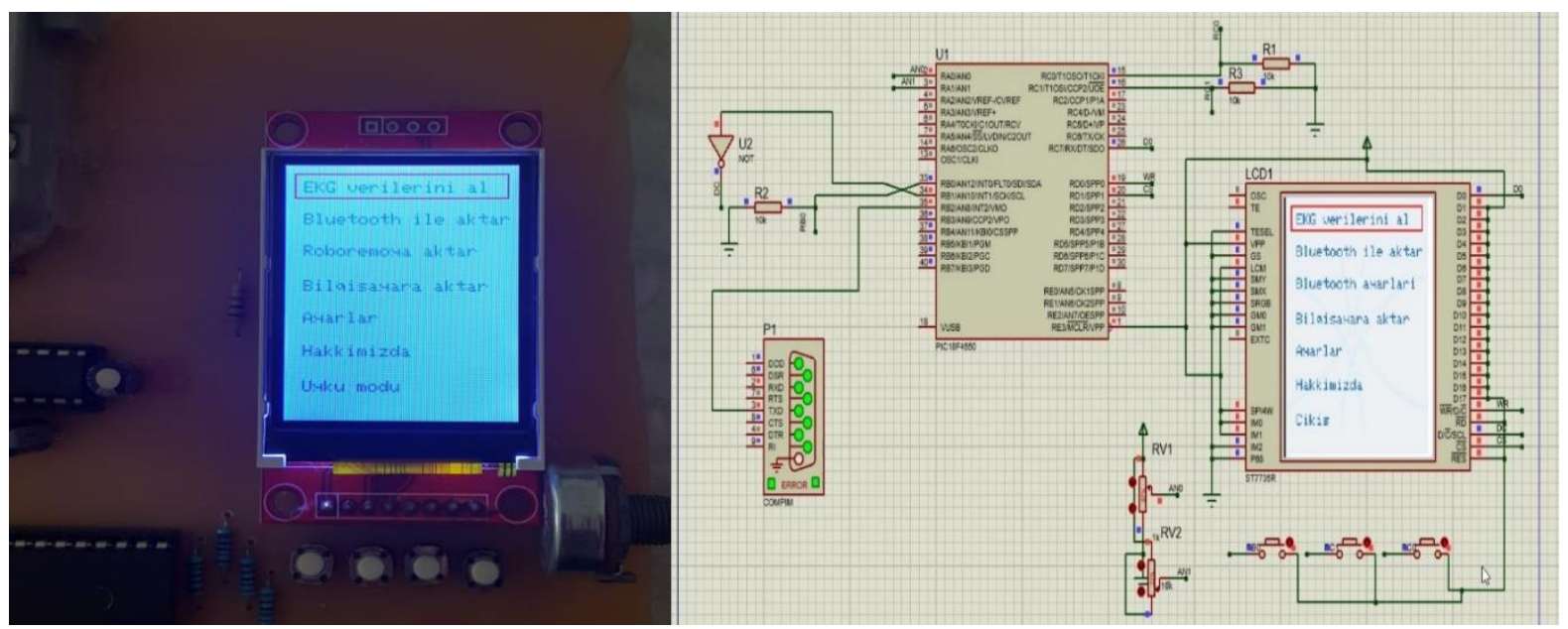

Figure 3. LCD screen interface 


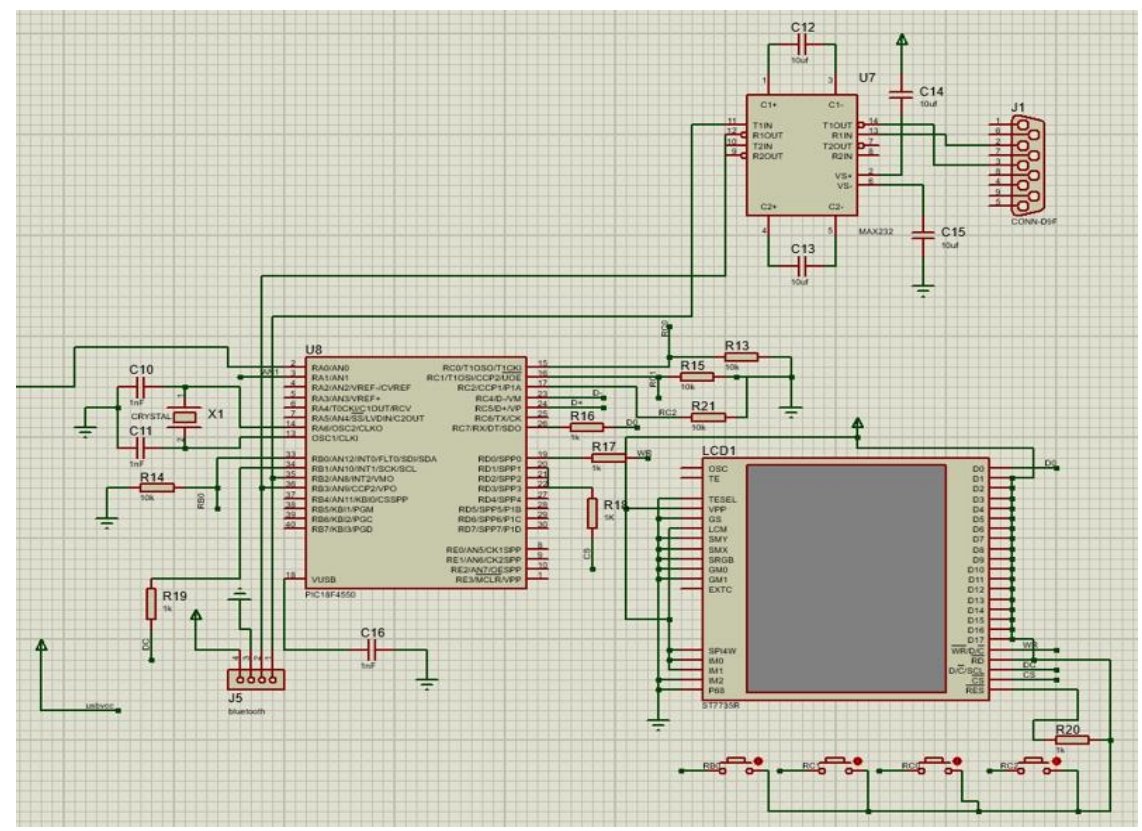

Figure 4. Digital circuit part of the ECG device

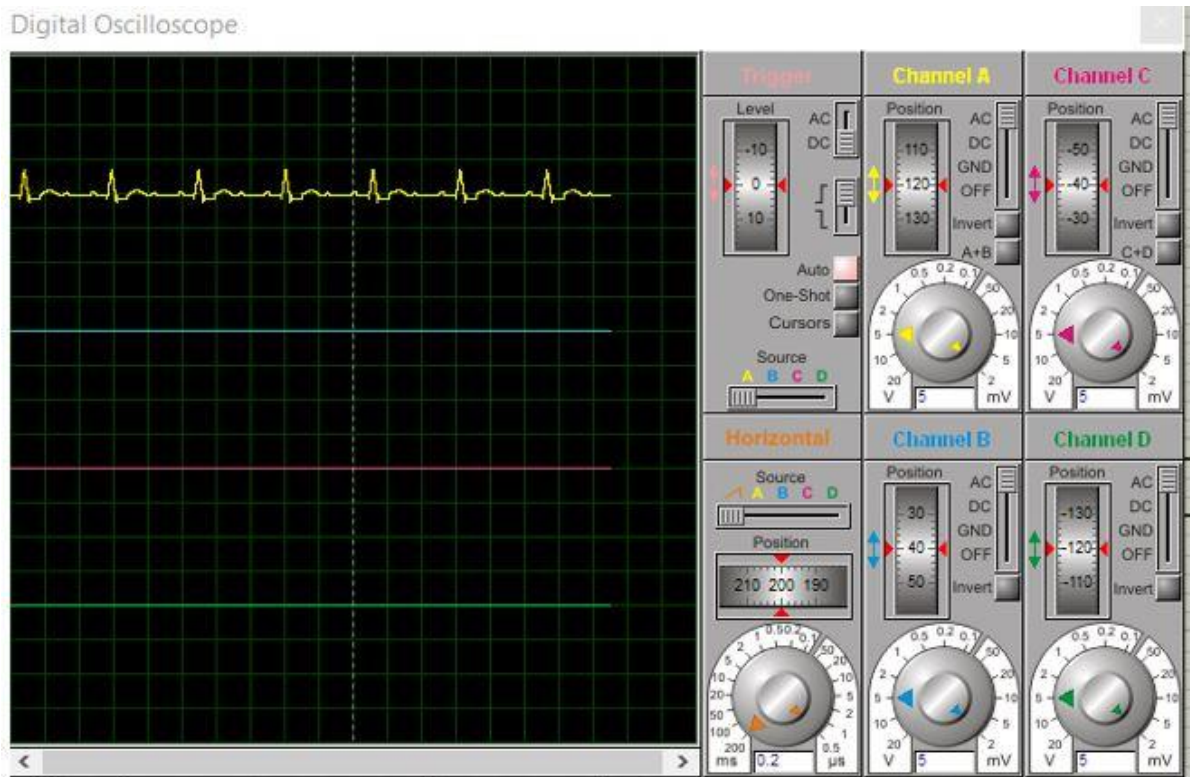

Figure 5. Output of simulation

\subsection{Implementation of the circuit}

The 2-dimensional and 3-dimensional drawings of the ECG device, whose preliminary work was completed in the simulation program, were made and the printed circuit part was formed (Figure 6). The printed circuit design was transferred onto the Printed Circuit Board (PCB) and the circuit connections were made (Figure 7) [15]. 

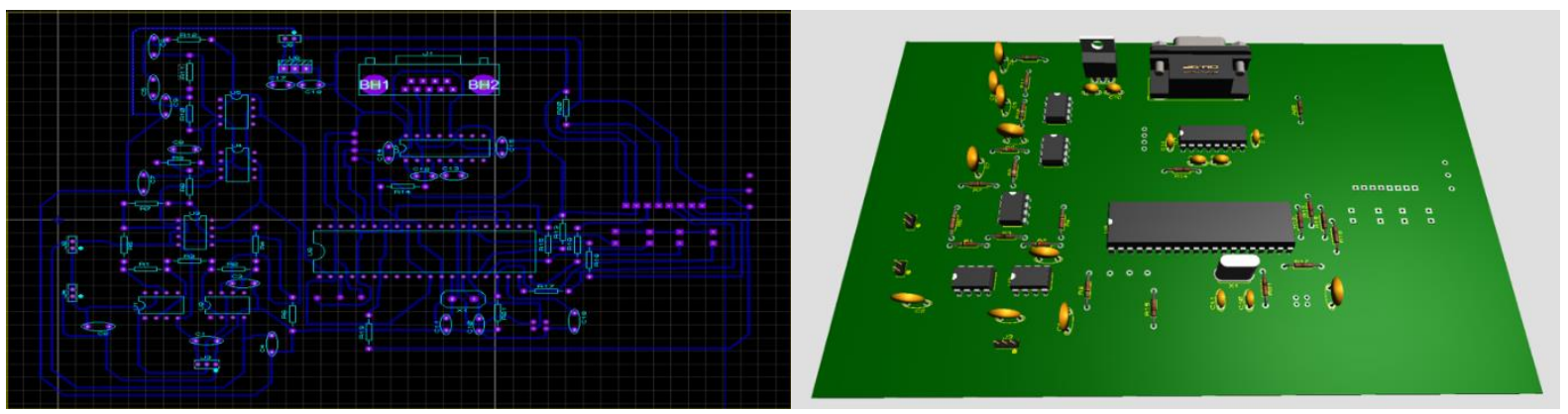

Figure 6. 2-dimensional and 3-dimensional drawings of the designed ECG device

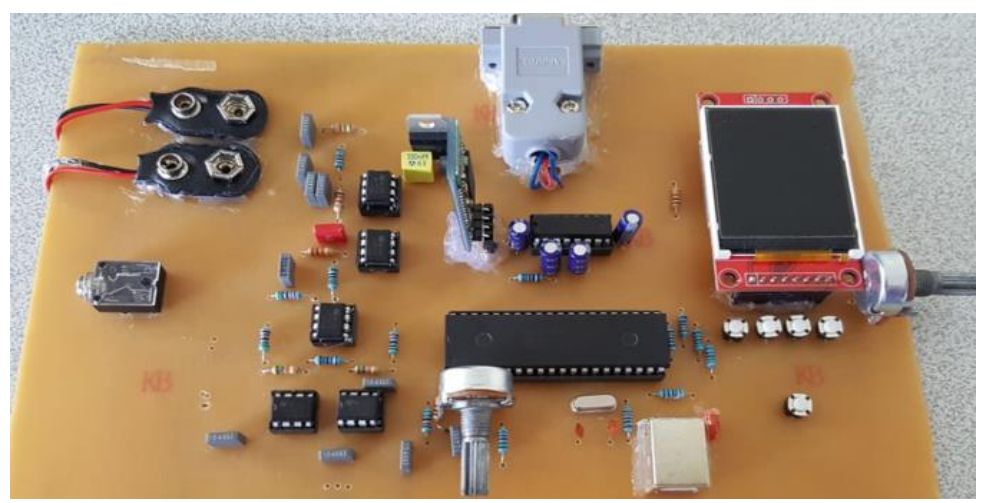

Figure 7. The designed ECG device transferred to the PCB

\section{Results}

The ECG system designed in the study digitizes the biopotential signals received from the individual with help of electrodes by using the PIC18F4550 microcontroller after the instrumentation amplifier and filtering processes. Then, ECG signals are displayed on the LCD screen with the help of HC06 Bluetooth module and RS-232 using the Universal Asynchronous Receiver Transmitter (UART) communication system. In Figure 8, the ECG signal obtained from the user is shown on the LCD screen and is shown on mobile devices by using HC06 Bluetooth module.

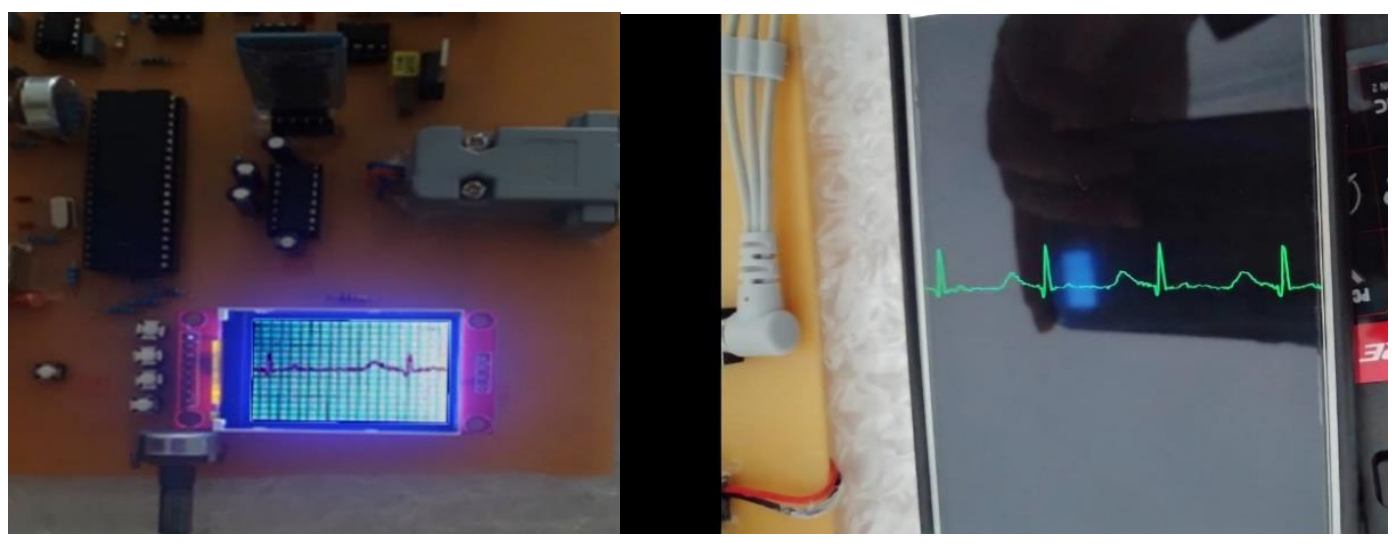

Figure 8. Transmitted ECG signal to the LCD screen and mobile device 


\section{Conclusion and Evaluation}

In this study, an ECG circuit design that includes various functions and aims to use flexibly is presented using a PIC18F4550 microcontroller. In the designed device, it is aimed to monitor the ECG signal from both the designed device screen and various electronic devices by using a HC06 Bluetooth module or RS-232. Individuals using the device designed with low cost by using a PIC18F4550 microcontroller will be able to monitor ECG data on any electronic device. The work done can be made more useful by reducing the size of the print circuit in the future, and it can be improved by ensuring that the data can be stored and transmitted to different places after being sent to the device. Additionally, interfaces can be created in different languages according to the country to be exported. Thanks to these methods, the obtained data by monitoring the heart signals of individuals 24/7 with a portable ECG can be evaluated and used for diagnosis and treatment.

\section{References}

[1] Mackay, J., \& Mensah, G. A. (2004). The atlas of heart disease and stroke. World Health Organization.

[2] Canal, M. R., Özkaraca, O., \& Hisar, Ç. (2011). Labview Tabanlı, Bilgisayar Destekli Gerçek Zamanlı EKG Cihazının Tasarımı. Akademik Bilişim, 10.

[3] Bilgin, S. N., \& Çamurcu, A. Y. (2017). Kablosuz EKG ve Pulse Oksimetre Uygulaması Sistem Tasarımı. 2. Ulusal Biyomedikal Cihaz Tasarımı ve Üretimi Sempozyumu, 16 Mayıs 2017.

[4] Ilhan, I., Y1ldız, İ., \& Kayrak, M. (2016). Development of a wireless blood pressure measuring device with smart mobile device. Computer methods and programs in biomedicine, 125, 94-102.

[5] İlhan, İ. (2017). Mobil cihaz kontrollü EKG holteri. Dicle Üniversitesi Mühendislik Fakültesi Mühendislik Dergisi, 8(1), 101-110.

[6] Mert, A., Seçgin, Ö., \& Akan, A. (2014). Sürekli Vücut Sıcaklığı Ölçümü İçin Biyotelemetri Cihaz Tasarımı The Design of a Biotelemetry Device for Continous Body Temperature Monitoring. Tip Teknolojileri Ulusal Kongresi, 312-315.

[7] Emrah, Ö. T. E. R., DEMIR, A. A., \& COŞKUN, Ö. MIKRODENETLEYİCI TEMELLİ PARMAK UCUNDAN NABIZ ÖLÇER DEVRESİ TASARIMI. Mühendislik Bilimleri ve Tasarım Dergisi, 4(2), 87-92.

[8] Wu, M. J., Shieh, S. F., Liao, Y. L., \& Chen, Y. C. (2016, July). ECG measurement system based on ARDUINO and android devices. In 2016 International Symposium on Computer, Consumer and Control (IS3C), IEEE (pp. 690-693).

[9] De Lucena, S. E., Sampaio, D. J., Mall, B., Meyer, M., Burkart, M. A., \& Keller, F. V. (2015, May). ECG monitoring using Android mobile phone and Bluetooth. In 2015 IEEE International Instrumentation and Measurement Technology Conference (I2MTC) Proceedings, IEEE (pp. 1976-1980).

[10] Sarkar, D., \& Chowdhury, A. (2015, January). Low cost and efficient ECG measurement system using PIC18F4550 microcontroller. In 2015 International Conference on Electronic Design, Computer Networks \& Automated Verification (EDCAV) (pp. 6-11), IEEE.

[11] Logeshwari, M., \& Subhalakshmi, N. Android platform based ecg arrhythmia and heart rate analysis system.

[12] Demır, B. E., Yorulmaz, F., \& Güler, İ. (2010, April). Microcontroller controlled ECG simulator. In 2010 15th National Biomedical Engineering Meeting (pp. 1-4), IEEE.

[13] Kohler, B. U., Hennig, C., \& Orglmeister, R. (2002). The principles of software QRS detection. IEEE Engineering in Medicine and biology Magazine, 21(1), $42-57$. 
[14] Webster, J. G. (Ed.). (2009). Medical instrumentation: application and design. John Wiley \& Sons.

[15] Çam, F., Orhanbulucu, F., Gökçe, S., Böyük, M., Akyürek, H. PIC18F4550 Mikrokontrolcü ile Bluetooth Modüllü Elektrokardiyografi Cihazı (Kayseri: Erciyes Üniversitesi, Mühendislik Fakültesi, Lisans Tezi, 2019) 